\title{
An Overview Of Quality In Higher Education In The West And Recommendations For Arab Universities
}

\author{
Hayat Diyen PG Dip (Essex), MA (York), Ph.D \\ (Sussex)
}

University Mohamed I, Oujda, Morocco.

\begin{abstract}
The paper proposes to study quality in higher education. It presents the definitional problems related to the concept of quality, and, then, it shows the approaches to implementing quality. Approaches to quality in higher education in most countries have started with an assumption that, for various reasons, the quality of higher education needs monitoring. While there are some conflicting attitudes towards systems of quality management in the West and criticism of the bureaucratic procedures related to some methods of quality assessment, the paper also discusses the situation in Arab countries regarding quality in higher education. To sum up, governments around the world are looking for higher education to be more responsive in face of the needs of a changing world.
\end{abstract}

\section{Introduction}

The concept of quality is not new and has existed ever since humans were ordained from God to toil on earth. In Islam for example, we read constantly that the reward for faith and doing good in Quran is paradise. In the Prophet's tradition we find the insistence on doing efficient deeds as a mark of faith in his statement "Blessed is the person who does a work efficiently". In Islamic philosophy we find Ibn Sina devoting a whole work on management, and for this purpose he used the term "tadbeer" which in Arabic means management in the literal sense. In different settings, quality is also a topic that was sought for in different cultures and religions. Darwin's theory of natural selection and the survival of the fittest is evidence from science that it is the highest quality of beings who are fit to adapt and survive. 
However, it seems that over the last two decades quality has become an urgent international concern sweeping higher education. Top on the agenda of the World Conference on Higher Education, which took place in Paris in October 1998, was quality as a concern for all. Quality has become the concern of governments internationally as is indicated by the International Academy for Quality (IAQ); the EFQM which was founded in 1988 and is in charge of managing the European Quality Awards like the Malcolm Baldrige Model in the USA and the Deming Prize in Japan; the British Quality Foundation; the Teaching Quality Academy; the European Center for Total Management (ECTQM) and so on. In October 2002, the UNESCCO launched its Global Forum on International Quality. UNESCO/OECD

Guidelines on "Quality Provision In Cross-Border Higher Education" Drafting Meeting 3, 17 18 January 2005 which deals with UNESCO's "Capacity Building Activities In Qualifications Recognition, Quality Assurance And Accreditation: Towards A Coherent Framework" has set out the following three strategic objectives for the medium-term 2002-2007:

Promoting education • as a fundamental right;

Improving the quality of education;

Promoting - experimentation, innovation and the diffusion and sharing of information (UNESCO, 2005, p.2).

In the developed countries higher education demanded more funding over the years to cater for the increase of student numbers. In return for funding, the governments required more control on the quality of education as to prepare graduates for employment. To mention only some countries where there are agencies or committees charged with quality assurance we have, the Council for Higher Education Accreditation (CHEA) in the USA, the Australian Universities Quality Agency (AUQA), Quality Assurance Agency (QAA) in the UK, and the Comité National d'Evaluation in France and Japanese University Accreditation Agency I Japan, etc.

The concern for quality in higher education is indeed caused by the cutback in public funding for universities and the government's requirement for value for money. Moreover, the move towards globalisation heightened the wave of competitiveness and made Western countries aware that they have to look for systems that are cost effective in funded services so as to compete at world stage. They fully realise that once competition enters in the higher education market, each provider must find ways to distinguish the service it offers from that of its competitors.

However, the economic forces of the market that internationalisation unleashed on governments led to see some of the ideals embraced by Western universities of traditional repute challenged. "Pursuit of truth", perceived as the goal of higher education in the West for centuries was always regarded by academics as a sufficient guarantee for investing in higher education to achieve the quality of outcomes. Expanding knowledge of students and enhancing their minds were part of the exceptional qualities offered by the university. It was only the elite who had the choice to pursue knowledge delivered by exceptional teachers and managed by exceptional staff. This served to make the universities enjoy some "academic independence of the kind articulated by von Humboldt, in the context of the establishment of the University of Berlin in 1809, expressed in the terms Lernfreiheit and Lehrfreiheit"( Penington,1998, p.256). This state of things changed because of some important factors that shaped the world since the 1980s and reinforced what is known in the global age we live in as the fragmentation of time and space which David Harvey (1990) calls time-space compression (quoted in UNESO, 2005). This new affair transformed the focus on truth and certainties to possibilities and probabilities. So, universities had to adapt to the changing world of knowledge and its laws. 
In developed countries, there was the clear commitment to academic autonomy, but when governments were faced with increased demand for funding which came as a result of the growth of student enrolments which transformed higher education to mass higher education (Trow, 1974), the governments saw the need for regulating the quality of provision and delivery in higher education. Many academics see that quality is no longer a choice or a luxury but a requirement for the 1990s. The concern for quality in education means caring about the goals, needs, desires and interests of customers and making sure they are met (Whitaker \& Moses 1994, p.76). But Lee Harvey sees that there has been little exploration of what quality is in higher education in his "An assessment of past and current approaches to quality in higher education". He considers that the failure to address the question of the nature of quality is behind the suspicion and alarm or amusement that academic staff regard the quality procedures imposed on them. They see them as tools of intrusion and inquisitorial systems of accountability. In fact, the new quality revolution was not accepted by all as it reflected a sense of control and policing over the well established profession of venerated academics who regard themselves as the generators of all the wealth of knowledge and high quality research that characterise Western universities for a long time.

What is the best definition of quality in education is a matter of great confusion, abstraction and controversy. Quality in higher education is a complex concept that has eluded clear definition (Nightingale \& ONeil, 1994; Lengnick-Hall \& Sanders, 1997; Marshall, 1998). Quality is most often defined as fitness for purpose related to the needs of the user/customer (Juran 1988). Lee Harvey, however, sees that this definition is rather vague as it is hard to define what fitness consists of. Harvey (1995) identifies five broad approaches to defining quality in higher education. These are quality as exceptional, perfection, fitness for purpose, value for money, and transformation. Transformative education is about adding value to the students by enhancing their attributes but it is also about empowering them as critical, reflective, transformative, lifelong learners (Astin, 1991; Harvey \& Knight, 1996). In the transformative model, quality relates to the way in which the educational experience enhances the knowledge, ability and skills of graduates as well as empowering the graduates (Harvey \& Knight, 1996, p. 8). Lee Harvey discusses the view of transformative education or what others call qualitative change that should be the goal for achieving quality in higher education. The transformation that quality education achieves in learners is what makes them fit to assume leadership roles to transform the world they live in. This is what makes Lee Harvey calls this transformation as positive and active. For him, education is a participative process. Students are not products, customers or consumers but they are participants. Education is not a marketable service for a customer but an ongoing process of transformation of the participant. This is one way how some scholars have defined quality in higher education.

Another definition is linked to the product and its compliance with defined requirements. Quality is defined in ISO lexicon as a desirable characteristic. So, a quality product or service is one that meets the needs and expectations of customers. Some concepts related to quality are quality control, quality assurance, quality management and quality assessment. Quality control is defined "as a set of activities or techniques whose purpose is to ensure that all quality requirements are being met." Quality assurance (Q.A.) is defined as a set of activities whose purpose is to demonstrate that an entity meets all quality requirements. Quality management includes all the activities that managers carry out in an effort to implement their quality policy. These activities include quality planning, quality control, quality assurance, and quality improvement. (ISO 8402, 1994).Quality improvement refers to anything that enhances an organisation's ability to meet quality requirements. Quality audits examine the elements of a quality management system in order to evaluate how well these elements comply with quality system requirements. Some scholars see that the term quality assessment as a better term than quality audit in the field of higher education (Juran, 1988) 
In a report (1993) presented to the Commission of the European Communities, we find the reasons for the attention given to quality in higher education, which are linked to the transformations that took place in education since the 1980s. Some of these reasons are linked to public funding and the need for more accountability to the funding bodies, the massification of higher education, democratisation and openness of institutions, internationalisation of education and the viability of higher education. It is the industrial and service sectors which were the first to utilizebb the systems of quality assurance. Afterwards, educational institutions which are seen, also, as organisations began to adopt the principles of quality assurance. Quality control is what measures up quality through standards that are defined along well-defined criteria to produce cost effective goods or services. But quality control can be, also, a tool for surveillance and intrusion for some academics. The concept of quality in this way is looked at as threatening the liberal establishment of their profession. The atmosphere evokes for them a top-down regime of control and inspection. For some critics, quality is a waste of energies and time as any bureaucratic procedures. Hence, a tension has emerged between quality as-"accountability procedures" and quality as"transformation". Some see that quality is not, in fact, producing the transformation in students to meet the requirements of a rapidly changing world. Lee Harvey warns that by focusing on accountability, the goal to make education a medium for transforming students is undermined. He shows that external quality monitoring can be counter- productive as it does not ensure a culture of internal continuous improvement that guarantees transformative processes of education. He gives some examples of countries that adopted external quality monitoring and shows the failure of ensuring a sustained commitment to quality improvement. In Spain, for example, "evaluation fever" has not achieved the expected effectiveness (Quoted in Harvey, 1995). In the United States, with a longer history of evaluation, informed commentators have suggested that the impact is only peripheral (Quoted in Harvey, 1995). In Australia, the quality of university teaching is increasingly the subject of political rhetoric, but doubt remains about both actual performance outcomes and the role and relevance of the Australian Universities Quality Agency (AUQA). Present quality procedures are found to be inadequate, and scepticism about AUQA 's capacity to achieve its aims. (Guest \& Duhs, 2003).

\section{Total Quality Management (TQM) In Higher Education}

Often the use of quality standards is combined with ideas about total quality management. Since the 1980 s there has been a movement by some great organisations, such as Ford Motor Company, Xerox, and Proctor and Gamble, towards the implementation of TQM. For the past few years, there have been pressures on higher educational institutions on their accountability, assessment and institutional effectiveness. Many are those who advocate the use of TQM in higher education through an analogy to business and industry.

TQM appeared promising as a strategy for improving effectiveness under organised conditions because it focused on setting very clear priorities for investing resources and reducing waste. It advocated organising personnel into teams committed to a mission that focused on the needs and preferences of external stakeholders. TQM called on the teams to base their decisions on objective data rather than on subjective assumptions. Some called this method continuous quality improvement or initiative (CQI)

Edwards Deming, the founding father of the principles of TQM, worked out with his colleague Walter A. Shewhart the theory of continuous improvement. Deming transported his theory of process improvement in the management of quality known as PDCA to Japanese businessmen. It is in Japan and not in the USA where Deming saw the application of his philosophy of management. His philosophy was adopted to achieve the quality of goods and 
services. The Japanese adopted it in 1950. Today, most organisations that have adopted the theory of continuous improvement have followed the approach of Deming, Juran, or Crosby. These organisations include manufacturing, service, health, education, military and government agencies. The principles of TQM are the relationship between suppliers and customers which is based on teamwork and collaboration, continuous improvement and self evaluation; and this does not mean policy of control, compliance and command. It is a system of ongoing process. It is the system which has to be examined and not individuals for the flaws. It encourages the spirit of leadership. The concepts of TQM are as follows: customer focus; continuous improvement; quality assurance of internal processes; process orientation; prevention instead of inspection to achieve quality.

Teaching and learning are viewed by the advocates of TQM as processes that can be managed like any other Total Quality Management (Chizmar, 1994). Chizmar advocates the implementation of TQM in the US educational institutions becausen he believes that it is a style of management that has worked for several decades in Japan. Now some colleges and universities are beginning to recognise that TQM values are more compatible with higher education than many existing management systems. The TQM was applied at some universities in the 1990s (Oregon State University, Arizona State University, Samford University, the State Board of Higher Education in North Dakota, Babson College, Fox Valley Technical College, The Pennsylvania State University, Purdue University, the University of Michigan, the University of Minnesota, University of Otago, etc.). But, it seems that the application of TQM is still not fully embraced. Concept of student as customer and the use of feedback seem to threaten the traditional view of professors as the sole judges who evaluate quality teaching (Chizmar, 1994), and that students are wholly dependent on them for knowledge. Under continuous quality improvement, a college or university seeks to improve the quality of what it uses, does and delivers. So, no state is final and the task of continuously check and improve are part of the process of learning. The ultimate goal is to enhance classroom effectiveness in order to improve student learning (Chaffee \& Sherr, 1992; Demming, 1982).

TQM is regarded by many as providing an appropriate strategy for a continuous monitoring and improvement of the quality of the organisation's performance. The implementation of TQM is mismanaged, however, if the manager thinks that TQM is being applied when it actually is not, and if universities treat students solely as customers of a teaching process. If quality assurance processes are limited, by the view of students as customers, to student evaluations of teachers, then this cannot be regarded as a true application of TQM. Students should be looked at as partners in the educational process and not just as customers. The students have to be co-workers in the educational organisation.

\section{ISO 9000: Quality management systems in higher education}

The concern for quality and performance is growing in society, with all the organisations being expected to become more accountable to the shareholders or the citizens (Van den Berghe, 1997, p.45). Since 1986/87 the series of International Standards (ISO 9000 series) have been an important starting point to higher quality. The success of ISO in industry shows that there is a big demand for internationally agreed standards. Certification is the proof that the clients of education are interested to see a proof for quality. A UK survey "ISO 9000 Does it work?" in 1995 by the Manchester business school lists the reasons for seeking certification:

- future customers likely demand for ISO 9000; 
- increase consistency of operations;

- maintain/improve market share;

- improve service quality;

- customer pressure;

- use as a good promotional tool;

- make operations more efficient;

- improve product quality (Van den Berghe ,p.49).

ISO 9000 is a system standard that is related to the assurance of quality. Its methods ensure that the product or service is in compliance with the customers' requirements. ISO 9000 is a system standard that has a wide applicability as it is a generic management system standard. It can be applied to any organisation, and is considered as applicable to educational systems especially in its eight management principles: customer focus, leadership; involvement of people; process approach; system approach to management; continual improvement; factual approach to decision making; and mutually beneficial supplier relationships. Therefore, the promotion of a high quality image and the response to external factors such as competitiveness and cost effectiveness and the growth of IT knowledge are some of the reasons which urged the productive as well as the educational sectors to be certified under ISO 9000 or ISO 9002.

\section{Recommendations for Arab universities}

We are in need of quality in Arab universities more than just rhetoric and political slogans used to receive the adulation of electorates or a fashionable catch all term or just simply as a passing fad. Instead of confidence in reform in the higher education of some Arab countries, we feel that there is a wave of doubt or disillusionment surrounding actual performance outcomes and the role and relevance of the actual agendas of reform. Real improvement in educational outcomes are likely only when "policy makers take to the road so as to gain first- hand experience of the problems faced by learners, teachers, principals and parents" (Diyen, 2004, p.221). Policy makers have to get out of their ivory towers to see how quality can be improved in education if they really mean to adopt the principles of quality improvement. Unfortunately, the development of quality assurance policies doest not always take place as an integral part of Arab higher education reforms processes. (UNESCO, 2005) We must ensure that quality is top priority of institutional management at the grass- roots level of Arab universities, otherwise it will continue to be just a dream.

The concern with quality assurance in Arab universities was only dealt with seriously at the 7th meeting of the Regional Committee responsible for the application of the Convention (1995). The ministers of Higher education, then, planned some resolutions to be adopted between 2000-2003 aiming at creating national agencies for quality assurance in higher education institutions. Until now, the number of states and institutions that have responded to the call of the Ministerial conferences is quite low. (UNESCO, 2005). At the same time, following a resolution by the Conference of the Ministers responsible of higher 
education in the Arab States, an expert committee set up by the Association of Arab universities has developed guidelines for self-assessment and accreditation of higher education institutions that were distributed to all members of the Association. "Many of the ideas and projects concerning quality assurance in higher education in the Arab States have not come to realization because of the lack of qualified human resources to carry them out" (UNESCO, 2005, p.6). When Arab countries are ready to face the challenges in higher education with commitment, freedom and courage they will, then, be able to transform their rhetoric on quality to practice. They will be aware that poor quality causes waste through rework, and causes them to lose their capital in the competitive world of knowledge.

We have to look for ways to develop a quality culture in society first, so the implementation of quality assurance in higher education will be rooted in the whole culture. Funding must be allocated to training administrators and professors to acquire knowledge about quality and its managements systems. Without actual sensitisation of the role that quality should play in promoting and developing society, we will continue to see quality illiteracy prevailing in our reform programmes.

The transformation of Arab universities to quality institutions is achievable only if the following challenges are surmounted. The first challenge that impedes any attempt to apply the systems of quality assurances in Arab universities is financial dependence of some Arab states, and the deteriorating economic conditions. Higher education in poor Arab universities suffers severe resource constraints. Most of the countries are dependent on foreign aid or on the World Bank loans. In the report of the UN published on 17 January 2005, Kofi A. Annan urges the donating countries who will compete for the millennium goals to invest in heath and education to alleviate poverty. He does not specify what type of education. When we read reports of the World Bank, we find that the latter is reducing lending to higher education and gives priority to basic education with the 1990 International Conference Education For all. (Samoff \& Carrol, 2003). So, what is the fate of quality in universities if the latter are at the mercy of charitable donors or lenders? Crisis, deterioration and dependence will be the mark for defining their provision. How can poor Arab countries avail themselves of the potential in IT knowledge when they are not even equipped with traditional bases of knowledge? When libraries are not equipped with books and do not possess refereed journals; and have no audiovisual and electronic equipments; and when students do not find chairs in classrooms; and when we have outdated curricula; and when professors have no incentives to improve teaching or to allocate energies to research; and when research is produced for international companies which fund projects that meet their own needs, how can we expect these institutions to apply the procedures for quality assurance? While universities in developed countries are competing to incorporate an "informatics culture", the universities in Arab countries have not reached even the minimum of international standards. It is beyond the scope of this paper to tackle this point, but what is obvious in such a deplorable situation is that poverty is a handicap for quality.

The second challenge is the relevance of higher education. In Arab universities there is no relationship between the productive and business sectors and studies and research. The research that is done by academics in universities to develop Arab countries relies on imported technologies and does not serve their local or regional needs. The result is that Arabs do not share in the production of information in the world but just receive it passively. But, if we continue to rely on imported information, we will never achieve autonomy and independence of higher education. If Arab countries do not design their own programmes for developing national policies to make higher education relevant to local and regional demands, higher educational institutions will not be responsive and producing development. Bernheim and Chaui write that "where the aims and methods of research are determined by links with the major research centres of the economically and militarily hegemonic countries," (UNESCO, 2004, p.1) some countries will continue to be dispossessed of the right to 
information which now forms the basis of economic power. Arab countries have to make their universities autonomous and capable of ensuring the application of scientific and technological innovations to meet the social and political needs of their own societies which are some of the important prerequisites of quality in higher education. One of the criteria of the improvement of quality is autonomy. Bernheim and Chaui's discussion of the negative effects of the channels of power which accompany globalisation can be used as a warning for Arab universities to call for concerted efforts from all the participants in higher education to address the issue of quality:

Insofar as economic hegemony belongs to financial capital and not productive capital, information prevails over knowledge proper since financial capital operates with purely virtual wealth, whose existence amounts to information itself. Such a situation produces, among other effects, one that is fairly precise: economic power is based on the possession of information which, as a result, becomes secret and ultimately constitutes a field of unprecedented economic and military competition while necessarily blocking democratic forces, which rest upon the right to information, both the right to obtain it and the right to produce and disseminate it. In other words, the knowledge society, from the information viewpoint, is governed by market (especially financial market) logic, so that it is neither appropriate nor conducive to the political action of civil society and the effective furtherance of requisite information and knowledge for social and cultural life (p.1).

The next challenge is linked to democratisation. We still see in Arab universities a tendency towards traditional teaching models while now the requirements for sustainable development and growth go beyond mere transmission-accumulation which characterise traditional teaching. The relationship of teacher/ learner should change. The teacher will be a co-worker with the student and this will make knowledge revolve around learning rather than teaching. If we analyse the relationship of teacher/learner in Arab universities, we will see traces of paternalism and tribal allegiance as characteristics of this relationship rather than the promotion of students as participants. This is however a natural reflection of the structure of top- down governance in Arab society in general. To allow students play the role of participants is one of the factors of quality assurance in democratic states. The transformation can occur only in an atmosphere where democracy and openness are dominant elements of the social and political establishment.

Another factor to the application of quality in Arab universities which is also linked to the democratisation of this sector is the role women should play in leadership positions in higher education. One of the tasks set out by the world declaration on higher education in the World Conference on Higher Education (Paris, October 1998) is the role given to women in decision making roles in higher education. But in Arab universities, women do not have the chance to use this right as we find only marginal roles given to them even in some so- called avant-guard countries which overpraise themselves for restructuring their societies on the modern paradigms of liberalism.

Another aspect of democratisation is linked to the appointment of high rank officials in Arab Universities. We have to train people to develop a culture of continuous improvement which can succeed only through openness and democracy. If the policy of favouritism continues in the choice of presidents, rectors, deans, departments chairs, the spirit of quality is undermined from within and can never be fulfilled. We need people who possess competencies in leadership, innovation, and team work; and, over all, quality of educational provision. We are in need of managers of quality education who can accommodate and initiate change, and who are not scared to lose their posts for taking initiatives and risks. We are in need of managers who are able to be self critical and ready for continuous improvement. 


\section{Conclusion}

To sum up, quality in higher education is a universal need for development and promotion. It is now an international preoccupation for all countries to implement quality management systems to ensure high quality learning and research. However, we have to be cautious about some of the effects of quality monitoring systems. A lot of work is needed to make professors and staff accept the principles of control and management. Expertise should be sought to clarify the definitional problems of the concept of quality and change the antipathetic feelings towards quality by some academics to faith in the efficiency of quality outcomes. The words control and management suggest centralisation and authoritarianism. But, if we see quality management as a method of controlling processes rather than personnel, we will cease to feel uneasy about it.

Still, if we keep on emphasising the economist agenda of knowledge over the humanist approach of knowledge, we end up by producing or training graduates who fit a marketable world that is doomed to change rather than preparing graduates who are capable of producing sustainable development. If we let our quality assessment of higher education be determined by the market logic and its laws, we will fail to produce citizens who are equipped with knowledge that generates effective and long term improvement which is a guarantee for sustainable development.

Furthermore, in adopting quality assurance procedures, we have to be aware of cultural diversity and identity. The institutions, the governments, the cultures of the world are different from one country to the next and the model of quality must not be only one for all. Differentiation is an asset and should not be undermined by the endorsement of a single approach to quality. This will create a spirit of conformity and may spoil efforts towards creativity and diversity which are the basis for quality improvement.

Moreover, the interference in higher education by either politics or economics will damage the inherent quality of the university. Frankfurter (quoted in Bok, 1982) explained that for "society's good, political power must abstain from intrusion into ... [the] freedom [of universities] except for reasons that are exigent and obviously compelling" (p.38). By seeking to rein in public expenditure in order to compete effectively in the new international era, we will tend to make education just as any commercial article which is devoid from the humanist sense that should characterise education. The role of a university should be to act as a guardian of freedom and critical thinking. But, if it gives in to too much control from government, it will cease to play this role. A university should prepare graduates to be armed with knowledge which allows them to have life long learning which serves to problem solving. They should be equipped to use their human rights so as to be participants in leadership roles. But, as long as there is inequality in the world we will never see the fulfilment of quality in teaching; and quality will continue to remain just a slogan which is used by politicians. As long as there is inequality of IT knowledge in the world, we will continue to have a division between the haves and the haves not of quality. As long as there is poverty and no democracy in the developing world and third world countries, we will continue to see a large part of the world has no equitable access to quality in higher education.

\section{References}


Astin, A. W. (1991). Assessment for excellence: The philosophy and practice of assessment and evaluation in higher education. New York: American Council on Education and Macmillan.

Bernheim,C.T \& Chaui, M.S. (2004). Challenges of the university in the knowledge society, five years after the World Conference on Higher Education. Forum Occasional Paper Series Paper, 4, Paris: UNESCO, ED-2004/WS/11.

Bok, D. (1982). Beyond the ivory tower: Social responsibilities of the modern university. Cambridge, MA: Harvard University Press.

Chaffee, E. and Sherr, L. (1992).Total Quality Management. In T. Connors, (Ed.), The Nonprofit Management Handbook: Operating Policies and Procedures. New York: John Wiley \& Sons, 3-21.

Chizmar, J.F (1994). Total Quality Management (TQM) of Teaching and Learning. Journal of Economic Education, 25 (2), 179-190.

Crosby, P. (1984). Quality Without Tears: The Art of Hassle-Free Management. New York: McGraw-Hill.

Deming, W. E. (1986). Out of crisis: Quality, productivity and competitive position. Cambridge: Center for Advanced Engineering Study, Massachusetts Institute of Technology.

Diyen, H. (2004). The Reform of Secondary Education in Morocco. Prospects IBE UNESCO, $34,(2), 211-222$.

Guest, R, \& Duhs, A. 2003. Quality assurance and the quality of university teaching. Australian Journal of Education, 47 (1), 40-57.

Harvey, L. (1995). The new collegialism: Improvement with accountability. Tertiary Education and Management, 2 (2), 153-60.

Harvey, L. \& Knight, P. (1996). Transforming higher education. Buckingham: Open University Press and Society for Research into Higher Education.

Harvey, L.(1998). An assessment of past and current approaches to quality in higher education. Australian Journal of Education, 42(3), 237-55.

ISO 8402, 1994 Edition http://praxiom.com/iso-definition.htm

Juran, J.M. (ed), (1988). Quality Control Handbook. New York: McGraw-Hill Book

Company.

Lengnick-hall, C.A. \& Sanders, M.M. (1997). Designing effective learning systems for management education. Academy of Management Journal, 40, 1334- 68.

MarshalL, S.J. (1998). Professional development and quality in higher education institutions of the 21st century. Australian Journal of Education, 42(3), 321- 34. 
Nightingale, P. \& Oneill, M. (1994). Achieving Quality Learning in Higher Education. London: Kogan Page.

Penington, D. (1998). Managing Quality in Higher Education Institutions of the 21st Century: A Framework for the Future. Australian Journal of Education, 42, (3), 256-270.

Samoff, J \& Carrol, B. (2003). From Manpower Planning to the Knowledge Era: World Bank Policies on Higher Education in Africa. Prepared for the UNESCO Forum on Higher Education, Research and Knowledge, 15 July. http://portal.unesco.org/education/en/file_download.php/e064c21981513e0d79d9df74 f7e3f717Samoff + doc.doc.

Trow, M. (1974). Problems in the transition from elite to mass higher education. Policies for Higher Education. General Report to the Conference on the Future Structure of PostSecondary Education. Paris: OECD.

UNESCO/OECD. (2005). Quality Provision In Cross-Border Higher Education. Drafting Meeting 3 ,17-18 January 2005 (OECD, Paris) UNESCO's Capacity Building Activities In Qualifications Recognition, Quality Assurance And Accreditation: Towards A Coherent Framework, 12 January, ED-04/RIQ/GF2 Guidelines on

Van den Berghe, W. (1997). Application of ISO 9000 Standards to Education and Training: Interpretation and guidelines in a European Perspective. Thessaloniki: CEDEFOP, 20-28.

Whitaker, K.S., \& Moses, M.C. (1994). The restructuring handbook. A guide to school revitalization. Boston, MA: Allyn and Bacon. 